\title{
Omentin-1, visfatin and adiponectin levels in relation to bone mineral density in Iranian postmenopausal women
}

\author{
Maasumeh Tohidi a, Samad Akbarzadeh a , Bagher Larijani ${ }^{\text {b }}$, Mohammadreza Kalantarhormozi a \\ Afshin Ostovar a , Majid Assadi ${ }^{\text {c }}$, Katayoun Vahdat ${ }^{\text {a }}$, Maryam Farrokhnia ${ }^{\mathrm{d}}$, Zahra Sanjdideh a , \\ Roya Amirinejad ${ }^{a}$, Iraj Nabipour ${ }^{\mathrm{a}, \mathrm{d}, *}$ \\ a Department of Endocrine and Metabolic Diseases, The Persian Gulf Tropical Medicine Research Centre, Bushehr University of Medical Sciences, 7514763448, Bushehr, Iran \\ ${ }^{\mathrm{b}}$ Endocrinology and Metabolism Research Center, Tehran University of Medical Sciences, Tehran, Iran \\ c The Persian Gulf Nuclear Medicine Research Centre, Bushehr University of Medical Sciences, Bushehr, Iran \\ ${ }^{\mathrm{d}}$ Department of Biochemistry, The Persian Gulf Marine Biotechnology Research Centre, Bushehr University of Medical Sciences, Bushehr, Iran
}

\section{A R T I C L E I N F O}

\section{Article history:}

Received 10 June 2012

Revised 22 July 2012

Accepted 6 August 2012

Available online 19 August 2012

Edited by: Felicia Cosman

\section{Keywords}

Adipocytokine

Omentin-1

Adiponectin

Visfatin

Adipose tissue

Menopause

\begin{abstract}
A B S T R A C T
The bone and fat interface is implicated in the pathogenesis of postmenopausal osteoporosis. The association between circulating omentin-1 levels and bone mineral density (BMD) in postmenopausal women has never been assessed. A total of 382 healthy postmenopausal women were randomly selected. Omentin-1, visfatin, adiponectin, the receptor activator of nuclear factor- $\kappa \mathrm{B}$ ligand (RANKL), osteoprotegerin, high sensitivity C-reactive protein, degradation products of C-terminal telopeptides of type I collagen, and osteocalcin were measured by highly specific enzyme-linked immunosorbent assay methods. BMD was determined for the lumbar spine (L2-L4) and the proximal femur using dual-energy X-ray absorptiometry. In multivariable-adjusted linear regression, serum omentin-1 levels were inversely correlated with BMD at the lumbar spine $(\beta=-0.11, p=0.020)$. In multiple regression analyses, serum visfatin and adiponectin levels were not significantly correlated with BMD at different skeletal sites after controlling for age, body mass index, and bone-related markers. However, the highest quartile of adiponectin compared to the lowest quartile, after adjusting for potential confounders, revealed an inverse association with BMD in the lumbar spine $(\beta=-0.19, p=0.010)$. In conclusion, circulating omentin- 1 levels had an inverse correlation with BMD at the lumbar spine in Iranian postmenopausal women. To further understand the role of omentin-1 in bone and mineral metabolism, large-scale longitudinal studies focusing on BMD and osteoporotic fractures are warranted.
\end{abstract}

(c) 2012 Elsevier Inc. All rights reserved.

\section{Introduction}

A growing body of clinical evidence has indicated that adipose tissue is an endocrine organ. This tissue produces a variety of biologically active protein factors called adipocytokines, which are pleiotropic molecules that not only regulate food intake and energy metabolism but also are implicated in the complex interactions between fat and bone $[1,2]$.

Adiponectin is one of the adipocytokines that are expressed specifically and abundantly in adipose tissue [3]. Adiponectin is negatively correlated with different obesity measures as well as insulin resistance indices [4,5]. It also plays an important role in glucose homeostasis and has anti-inflammatory and anti-atherogenic properties [6]. Adiponectin also influences osteoclastogenesis indirectly by

\footnotetext{
* Corresponding author at: The Persian Gulf Tropical Medicine Research Center, Boostan 19 Alley, Imam Khomeini St, Bushehr, IR, Postal Code: 7514763448, Iran. Fax: +987712541828 .

E-mail address: inabipour@gmail.com (I. Nabipour).
}

stimulating the receptor activator of nuclear factor- $\kappa \mathrm{B}$ ligand (RANKL) and inhibiting osteoprotegerin (OPG) production in osteoblasts [7].

Visfatin (nicotinamide phosphoribosyltransferase or pre-B-cell colony-enhancing factor 1 ) is secreted abundantly by the visceral fat of humans and mice and mimics the action of insulin [8]. Human studies have shown inconsistent and conflicting results regarding associations between visfatin and the insulin-mimetic effect, insulin resistance, beta cell function impairment, adiposity, subcutaneous versus visceral fat distribution, and diabetes [9]. Visfatin acts as nicotinamide phosphoribosyl transferase (NAMPT), an enzyme involved in the nicotinamide adenine dinucleotide $(\mathrm{NAD}+)$ salvage pathway [10]. The age-related reduction of NAMPT activity may be involved in senile osteoporosis because treatment with the NAMPT inhibitor FK866 increases adipocyte formation and reduces mineralization in primary cultured bone marrow stromal cells [11].

Omentin-1 is a novel $34 \mathrm{kDa}$ adipocytokine, which in comparison with subcutaneous adipose tissue, is highly and selectively expressed in visceral adipose tissue [12,13]. Furthermore, omentin- 1 enhances insulin action and Akt phosphorylation [14]; it is inversely related to obesity [15] and is down regulated by insulin and glucose [13]. In an 
in vitro study to investigate the effects of omentin-1 on bone metabolism, omentin- 1 reduced osteoclast formation by stimulating OPG and inhibiting RANKL production in osteoblasts [16].

Although adiponectin has been investigated as a potential contributor to bone metabolism in women [4,17-19], the relationship between circulating levels of visfatin and BMD in postmenopausal women has not been fully elucidated. Moreover, there is no human study in the medical literature to investigate circulating omentin-1 levels in relationship to BMD in postmenopausal women. However, we recently reported a correlation between omentin-l concentrations with BMD in multiple sclerosis [20], and Guo LJ [21] investigated the relationship between serum omentin-1 level and BMD in girls with anorexia nervosa. The aim of the current study was to correlate omentin-1, visfatin, and adiponectin levels with BMD, bone-related mediators, and cytokines in healthy Iranian postmenopausal women in order to determine whether these adipocytokines may be related to BMD.

\section{Materials and methods}

\section{Community sampling}

The study design was described in a previous study [22]. In brief, 382 postmenopausal women who participated in the Iranian Multicentral Osteoporosis Study were evaluated from April 4 to September 22, 2006. The mean age (mean \pm SD) of the women was $59.0 \pm 7.5$ years (range, $50-83$ years). They were randomly selected from 13 clusters in Bushehr Port (the center of Bushehr province, which has the longest border with the Persian Gulf). All were community dwelling and ambulatory. The following exclusion criteria were used: 1) the known presence of generalized bone diseases including hyperparathyroidism, hypoparathyroidism, thyroid disorders, rheumatoid arthritis, Cushing disease, and steroid-induced osteoporosis; renal osteodystrophy; or other metabolic diseases; 2 ) a history of malignant diseases, type 1 diabetes mellitus, and liver diseases; 3 ) drug addiction; and 4) restriction to bed rest within the last 2 weeks after an illness or complete bed rest for 3 months.

\section{Physical examinations}

A stadiometer was used to measure height and weight. Heavy outer garments and shoes were removed before the participants' height and weight were measured. Body mass index (BMI) was calculated. Waist circumference was defined at the midway level between the costal margins and the iliac crests. Hip circumference was measured at the level of the greater trochanters.

BMD was determined for the lumbar spine (L2-L4) and proximal femur (neck) using dual-energy X-ray absorptiometry on an Osteocore II bone densitometer (Osteocore II Osteodensitometer; Medilink, France). To eliminate operator discrepancies, the same operator tested all the women during the study. Duplicate measurements were obtained from 30 women who agreed to undergo a repeat assessment on the same day, and the precision errors were calculated using the root mean square method. The coefficients of variation (CVs; precision) of measurements of the lumbar spine and femoral neck were $0.8 \%$ and $1.6 \%$, respectively.

\section{Laboratory measurements}

A fasting blood sample was taken. All samples were promptly centrifuged and separated, and the analyses were carried out at the Persian Gulf Health Research Center on the day of blood collection.

The measurement of C-reactive protein (CRP) by a high sensitivity (hs) CRP assay and CRP HS enzyme-linked immunosorbent assay (ELISA) (DRG International) was conducted. The minimum detectable concentration of the CRP HS ELISA assay was estimated to be $0.1 \mathrm{mg} / \mathrm{L}$.
In addition, the functional sensitivity was determined to be $0.1 \mathrm{mg} / \mathrm{L}$ (as determined with inter-assay coefficient of variation $<20 \%$ ).

Serum OPG levels were measured using an ELISA commercial kit (Biomedica Gruppe, Vienna, Austria). The detection limit of the assay was $0.14 \mathrm{pmol} / \mathrm{L}$. The mean intra- and inter-assay coefficients of variation of the OPG assay were $4 \%$ to $10 \%$ and $7 \%$ to $8 \%$, respectively.

The receptor activator of nuclear factor- $\kappa B$ ligand (RANKL) levels was measured using an ELISA with an additional enhancement system (ampli-sRANKL; Biomedica Gruppe). The detection limit of the assay was $0.4 \mathrm{pg} / \mathrm{mL}$. The mean intra-assay and inter-assay CVs of the RANKL assay were $8 \%$ to $9 \%$ and $6 \%$ to $3 \%$, respectively.

The N-MID Osteocalcin ELISA (Nordic Bioscience Diagnostics A/S) was used for the quantitative measurement of osteocalcin in sera. The intra-assay CVs for the low $(7.0 \mathrm{ng} / \mathrm{mL})$, medium $(21.8 \mathrm{ng} / \mathrm{mL})$, and high $(43.2 \mathrm{ng} / \mathrm{mL})$ values were $3.4 \%, 2.0 \%$, and $2.4 \%$, respectively.

The serum CrossLaps enzyme-linked immunosorbent assay (Nordic Bioscience Diagnostics A/S, Herlev, Denmark) was used for the quantification of degradation products of C-terminal telopeptides of type I collagen in sera. The intra-assay CVs for low $(0.242 \mathrm{ng} / \mathrm{mL})$, medium $(0.375 \mathrm{ng} / \mathrm{mL})$, and high $(0.476 \mathrm{ng} / \mathrm{mL})$ values were $5.4 \%, 5.0 \%$, and $5.1 \%$, respectively.

Serum alkaline phosphatase was determined by spectrophotometry using p-nitrophenylphosphate as substrate (Pars Azemon, Tehran, Iran). Intra- and inter-assay CVs were $1.5 \%$ and $2.6 \%$, respectively.

Serum omentin-1 concentrations were measured using manual omentin-1 (human) detection (ELISA kit [intelectin-1 (human) ELISA kit, Apotech Corporation, Switzerland]). The detection limit of the assay was $0.4 \mathrm{ng} / \mathrm{mL}$ (range 0.5 to $32 \mathrm{ng} / \mathrm{mL}$ ). The mean intra-assay and interassay CVs of the omentin-1 assay were $4.51 \%$ to $7.4 \%$ and $4.19 \%$ to $9.27 \%$, respectively. The antibodies used in this kit are specific to measurement of natural and recombinant human omentin-1.

To detect visfatin in the serum samples, commercially (Cat. No. V0523EK) available enzyme-linked immunosorbent assay kit (AdipoGen, Seoul, Korea) was used according to the manufacturer's instructions. The assay sensitivity for visfatin was $0.10 \mathrm{ng} / \mathrm{mL}$; the intraand inter-assay coefficients of variance were $3.8-5.5 \%$ and $6.4-9.5 \%$, respectively.

To detect adiponectin in the serum samples, commercially (Cat. No.AG-45A-0001EK-KI01) available enzyme-linked immunosorbent assay kits (AdipoGen, Incheon, Korea) were used according to the manufacturer's instructions. The limit of detection of the assay was $100 \mathrm{pg} / \mathrm{mL}$; the intra- and inter-assay coefficients of variance were $2.9 \%$ to $3.8 \%$ and $2.8 \%$ to $5.5 \%$, respectively.

\section{Statistical analysis}

Normal distribution of the data was ascertained by the KolmogorovSmirnov test. Because the distributions of serum hs-CRP, OPG, RANKL, osteocalcin, and adipocytokines were skewed, logarithmically transformed values were used for the statistical analysis.

Pearson correlation analysis was used to study the relationships between adipocytokine values and the anthropometric and biochemical variables. Partial correlation analysis was performed to assess the association between adipocytokine levels, anthropometric indices, and biochemical variables, with adjustment for age and weight. The standard multiple linear regression models were used to assess the association between circulating adipocytokine levels (independent variable) and BMD at a number of skeletal sites (dependent variables). The models were adjusted for age, BMI, and bone-related markers. Probability values $<5 \%$ were considered statistically significant. All statistical analyses were performed using the PASW Statistics GradPack 18 (SPSS Inc., Chicago, IL).

\section{Results}

The characteristics of the study participants are shown in Table 1. The age (mean \pm SD) of the women was $59.0 \pm 7.5$ years. The prevalence of 
Table 1

Basic characteristics of bone related variables and adipocytokines in an Iranian postmenopausal population (382 participants).

\begin{tabular}{|c|c|c|}
\hline & Mean or median & $\begin{array}{l}\text { SD or interquartile } \\
\text { range }\end{array}$ \\
\hline Age, y & 59.0 & 7.50 \\
\hline Body max index, $\mathrm{kg} / \mathrm{m}^{2}$ & 28.34 & 4.73 \\
\hline Waist-to-hip ratio & 0.92 & 0.06 \\
\hline Calcium, mg/dL & 9.84 & 0.64 \\
\hline Phosphorus, mg/dL & 3.93 & 0.50 \\
\hline Alkaline phosphatase, U/L & 245.36 & 90.21 \\
\hline CrossLaps, ng/mL & 0.59 & $0.43-0.79$ \\
\hline Osteocalcin, ng/mL & 9.82 & $8.18-12.58$ \\
\hline RANKL, pg/mL & 1.64 & $0.96-2.96$ \\
\hline $\mathrm{OPG}, \mathrm{pg} / \mathrm{mL}$ & 72.1 & $57.05-95.0$ \\
\hline hs-CRP, mg/L & 2.0 & $0.94-4.23$ \\
\hline Omentin-1, ng/mL & 12.37 & $7.90-18.32$ \\
\hline Visfatin, $\mathrm{ng} / \mathrm{mL}$ & 2.92 & $1.65-4.41$ \\
\hline Adiponectin, $\mu \mathrm{g} / \mathrm{mL}$ & 10.84 & $7.84-14.17$ \\
\hline Femoral neck BMD, $\mathrm{g} / \mathrm{cm}^{2}$ & 0.844 & 0.184 \\
\hline Lumbar BMD, $\mathrm{g} / \mathrm{cm}^{2}$ & 0.946 & 0.186 \\
\hline
\end{tabular}

Data are means or medians and standard deviations (SDs) or interquartile ranges. RANKL, receptor activator of nuclear factor- $\kappa \mathrm{B}$ ligand; hs-CRP, high-sensitivity C-reactive protein; OPG, osteoprotegerin; BMD, bone mineral density.

consumption of oral calcium, vitamin D supplementation, and hormone therapy was $5.7 \%, 4.2 \%$, and $1.0 \%$, respectively. None of the participants had a history of alcohol consumption. According to the World Health Organization (WHO) criteria (a BMD 2.5 standard deviations or more below the mean for young white adult women; report of a WHO Study Group, 1994), 38 women (9.2\%) were considered osteoporotic. BMD at the lumbar spine and femoral neck decreased progressively with increases in age $(\mathrm{p}<0.0001)$.

The results of the serum levels of the studied adipocytokines are shown as median and interquartile range in Table 1.

\section{Omentin-1}

Bivariate correlation analysis showed a correlation between omentin1 and serum phosphorus $(\mathrm{r}=0.12, \mathrm{p}=0.026)$, waist circumference $(\mathrm{r}=$ $-0.12, p=0.024)$, and BMD at the lumbar spine $(r=-0.13, p=0.017)$. However, no significant correlations were found between omentin- 1 and age, BMI, bone turnover markers, hs-CRP, markers of bone metabolism, and BMD at the femoral neck in postmenopausal women $(\mathrm{p}>0.05$, Table 2).In the total population, correlations between serum omentin-
Table 3

Multiple linear regression analysis for the association between adipocytokines (independent variables), and bone mineral density (dependent variables) in postmenopausal women.

\begin{tabular}{|c|c|c|c|c|c|}
\hline & & \multicolumn{2}{|c|}{ Lumbar BMD } & \multicolumn{2}{|c|}{ Femur neck BMD } \\
\hline & & $\beta$ & $\mathrm{p}$ & $\beta$ & $\mathrm{p}$ \\
\hline \multirow[t]{3}{*}{ Omentin-1 } & Age-adjusted & -0.12 & 0.018 & -0.46 & 0.646 \\
\hline & Age-, BMI-adjusted & -0.09 & 0.040 & 0.01 & 0.776 \\
\hline & Full model $^{\mathrm{a}}$ & -0.11 & 0.020 & 0.02 & 0.612 \\
\hline \multirow[t]{3}{*}{ Visfatin } & Age-adjusted & 0.12 & 0.019 & 0.93 & 0.073 \\
\hline & Age-, BMI-adjusted & 0.03 & 0.439 & 0.01 & 0.994 \\
\hline & Full model $^{\mathrm{a}}$ & 0.03 & 0.522 & -0.01 & 0.758 \\
\hline \multirow[t]{3}{*}{ Adiponectin } & Age-adjusted & -0.13 & 0.013 & -0.08 & 0.124 \\
\hline & Age-, BMI-adjusted & -0.07 & 0.148 & -0.01 & 0.737 \\
\hline & Full model $^{\mathrm{a}}$ & -0.06 & 0.248 & -0.02 & 0.725 \\
\hline
\end{tabular}

BMI, body mass index; BMD, bone mineral density.

a Full model included age, BMI, hs-CRP, osteoprotegrein, RANKL, CrossLaps, osteocalcin, alkaline phosphatase, smoking, hormone replacement therapy, and supplementation with calcium and vitamin D in addition to adipocytokines (omentin-1, visfatin, or adiponectin).

1levels and serum phosphorus $(r=0.12, p=0.033)$ and BMD at the lumbar spine $(-0.11, \mathrm{p}=0.044)$ persisted after adjustment for age and weight (Table 2).

Table 3 shows the results of multiple linear regression analyses for the correlation between circulating omentin-1 levels and BMD at different sites after controlling for age, anthropometric measures, and bone-related variables.

In multiple regression analyses, serum omentin-1 levels showed significant negative correlation with BMD at the lumbar area after controlling for age, BMI, and bone-related markers $(\beta=-0.11$, $\mathrm{p}=0.020)$.

\section{Visfatin}

Bivariate correlation analyses for circulating visfatin levels in relation to anthropometric measures and bone-related biochemical markers are presented in Table 2. Age- and weight-adjusted visfatin levels had correlations with BMI $(r=0.14, p=0.009)$, hs-CRP $(r=0.25, p<0.0001)$, osteocalcin $(r=-0.15, p=0.009)$, CrossLaps $(r=0.11, p=0.039)$, calcium $(\mathrm{r}=0.14, \mathrm{p}=0.011$, and adiponectin $(\mathrm{r}=-0.17, \mathrm{p}=0.002)$ levels (Table 2). However, no significant correlations were found between age- and weight-adjusted visfatin and OPG, RANKL, alkaline phosphatase, phosphorus, and BMD at all sites in postmenopausal women ( $>0.05$, Table 2$)$.

Table 2

Unadjusted, and age- and weight adjusted correlation analyses between adipocytokines and bone related variables in postmenopausal women.

\begin{tabular}{|c|c|c|c|c|c|c|c|c|c|c|c|c|}
\hline & \multicolumn{4}{|c|}{ Omentin-1 } & \multicolumn{4}{|l|}{ Visfatin } & \multicolumn{4}{|c|}{ Adiponectin } \\
\hline & \multicolumn{2}{|c|}{ Unadjusted } & \multicolumn{2}{|l|}{ Adjusted } & \multicolumn{2}{|c|}{ Unadjusted } & \multicolumn{2}{|l|}{ Adjusted } & \multicolumn{2}{|c|}{ Unadjusted } & \multicolumn{2}{|l|}{ Adjusted } \\
\hline & $r$ & $\mathrm{p}$ & $r$ & $\mathrm{p}$ & $\mathrm{r}$ & $\mathrm{p}$ & $r$ & $\mathrm{p}$ & $r$ & $\mathrm{p}$ & $r$ & $\mathrm{p}$ \\
\hline Age & 0.028 & 0.619 & & & 0.024 & 0.665 & & & 0.180 & 0.001 & & \\
\hline BMI & -0.079 & 0.157 & -0.035 & 0.529 & 0.161 & 0.004 & 0.145 & 0.009 & -0.161 & 0.004 & -0.075 & 0.179 \\
\hline Waist circumference & -0.125 & 0.024 & -0.079 & 0.155 & 0.150 & 0.007 & 0.091 & 0.105 & -0.144 & 0.009 & -0.080 & 0.150 \\
\hline hs-CRP & -0.024 & 0.664 & 0.001 & 0.988 & 0.285 & $<0.0001$ & 0.255 & $<0.0001$ & -0.134 & 0.016 & -0.096 & 0.087 \\
\hline OPG & 0.025 & 0.655 & 0.016 & 0.778 & 0.055 & 0.327 & 0.055 & 0.327 & 0.024 & 0.666 & -0.102 & 0.067 \\
\hline RANKL & 0.020 & 0.727 & 0.015 & 0.791 & -0.010 & 0.866 & -0.002 & 0.971 & 0.057 & 0.310 & 0.072 & 0.202 \\
\hline Osteocalcin & -0.019 & 0.738 & -0.048 & 0.394 & -0.155 & 0.006 & -0.148 & 0.009 & 0.200 & $<0.0001$ & 0.151 & 0.007 \\
\hline CrossLaps & 0.026 & 0.639 & 0.007 & 0.900 & -0.128 & 0.021 & -0.115 & 0.039 & 0.156 & 0.005 & 0.097 & 0.084 \\
\hline Alkaline phosphatase & -0.047 & 0.400 & -0.062 & 0.268 & -0.021 & 0.711 & -0.014 & 0.799 & 0.030 & 0.573 & 0.005 & 0.925 \\
\hline Calcium & 0.066 & 0.232 & 0.046 & 0.407 & 0.130 & 0.019 & 0.141 & 0.011 & -0.130 & 0.013 & -0.143 & 0.010 \\
\hline Phosphorus & 0.123 & 0.026 & 0.118 & 0.033 & 0.087 & 0.118 & 0.085 & 0.129 & -0.050 & 0.365 & -0.042 & 0.452 \\
\hline Femur neck BMD & -0.034 & 0.542 & 0.005 & 0.935 & 0.084 & 0.130 & 0.031 & 0.581 & -0.140 & 0.008 & -0.033 & 0.560 \\
\hline Lumbar BMD & -0.132 & 0.017 & -0.112 & 0.044 & 0.113 & 0.043 & 0.068 & 0.223 & -0.190 & $<0.0001$ & -0.093 & 0.097 \\
\hline Visfatin & 0.037 & 0.502 & 0.046 & 0.411 & & & & & -0.180 & 0.001 & -0.172 & 0.002 \\
\hline Adiponectin & -0.016 & 0.771 & -0.022 & 0.696 & -0.180 & 0.001 & -0.172 & 0.002 & & & & \\
\hline Omentin-1 & & & & & 0.037 & 0.502 & 0.046 & 0.411 & -0.016 & 0.771 & -0.022 & 0.696 \\
\hline
\end{tabular}

RANKL, receptor activator of nuclear factor- $\kappa B$ ligand; hs-CRP, high-sensitivity C-reactive protein; OPG, osteoprotegerin; BMD, bone mineral density. 
In multiple regression analyses, serum visfatin levels were not significantly correlated with BMD at different sites after controlling for age, BMI, and bone-related markers (Table 3).

Analysis by the highest quartile versus the lowest quartile of visfatin did not reveal an association with BMD in either the lumbar spine or femoral neck (Table 4).

\section{Adiponectin}

Serum adiponectin showed correlations with age, BMI, waist circumference, hs-CRP, bone turnover markers, calcium, visfatin levels, and BMD at all sites (Table 2). In bivariate analyses, serum adiponectin levels had significant negative correlations with BMD at the lumbar spine $(\mathrm{r}=-0.14, \mathrm{p}=0.008)$ and femoral neck $(\mathrm{r}=-0.19,<0.0001$; Table 2). This correlation did not persist when adiponectin levels were adjusted for age and weight (Table 2). However, correlations between serum adiponectin levels and serum osteocalcin $(r=0.15, p=0.007)$ and visfatin $(\mathrm{r}=-0.17, \mathrm{p}=0.002)$ persisted after adjustment for age and weight (Table 2).

In multiple regression analyses, serum adiponectin levels were not significantly correlated with BMD at different sites after controlling for age, BMI, and bone-related markers (Table 3). However, the highest quartile of adiponectin compared to the lowest quartile revealed an inverse association with BMD in the lumbar spine $(\beta=-0.33$, $\mathrm{p}<0.0001$ ). This reverse association persisted after adjustment for age, BMI, and bone-related indicators $(\beta=-0.19, p=0.010$; Table 4$)$.

The highest quartile versus the lowest quartile of adiponectin level had significant association with lower OPG levels after adjustment for age and $\mathrm{BMI}(\mathrm{p}=0.019)$.

\section{Discussion}

In current study of overweight/obese postmenopausal women, we found that omentin-1 was a predictor of lower lumbar BMD. Moreover, the highest quartile versus the lowest quartile of circulating adiponectin levels was predictive of BMD at the lumbar spine. However, our analyses revealed no significant association between serum visfatin levels and BMD in either the lumbar spine or femoral neck.

Omentin-1 is a newly identified depot-specific adipokine in human adipose tissue that may modulate insulin sensitivity by its paracrine or endocrine functions [13].It was shown that omentin-1 levels were inversely correlated with measures of obesity and insulin resistance and positively correlated with adiponectin levels [15]. It was also reported that omentin-1 levels were lower in patients with metabolic syndrome than in controls [23]. Omentin inhibits vascular

\section{Table 4}

Multiple linear regression analysis for the association between the highest quartiles of adipocytokine levels versus the lowest quartiles of adipocytokine levels (independent variables), and bone mineral density (dependent variables) in postmenopausal women.

\begin{tabular}{|c|c|c|c|c|c|}
\hline & & \multicolumn{2}{|c|}{ Visfatin } & \multicolumn{2}{|c|}{ Adiponectin } \\
\hline & & $\beta$ & $\mathrm{p}$ & $\beta$ & $\mathrm{p}$ \\
\hline \multirow[t]{5}{*}{ Lumbar BMD } & Unadjusted & 0.04 & 0.556 & -0.33 & $<0.0001$ \\
\hline & Age-adjusted & 0.13 & 0.060 & -0.24 & 0.002 \\
\hline & Age-, weight-adjusted & 0.01 & 0.869 & -0.20 & 0.002 \\
\hline & Age-, waist-adjusted & 0.04 & 0.556 & -0.19 & 0.004 \\
\hline & Full model $^{\mathrm{a}}$ & 0.01 & 0.949 & -0.19 & 0.010 \\
\hline \multirow[t]{5}{*}{ Femur neck BMD } & Unadjusted & 0.15 & 0.043 & -0.25 & 0.001 \\
\hline & Age-adjusted & 0.16 & 0.020 & -0.14 & 0.057 \\
\hline & Age-, weight-adjusted & 0.05 & 0.355 & -0.10 & 0.103 \\
\hline & Age-, waist-adjusted & 0.07 & 0.265 & -0.09 & 0.150 \\
\hline & Full model $^{\mathrm{a}}$ & 0.03 & 0.662 & -0.10 & 0.166 \\
\hline
\end{tabular}

BMI, body mass index; BMD, bone mineral density.

a Full model included age, BMI, hs-CRP, osteoprotegrein, RANKL, CrossLaps, osteocalcin, alkaline phosphatase, smoking, hormone replacement therapy, and supplementation with calcium and vitamin $D$ in addition to the highest quartile of adiponectin or visfatin levels versus the lowest quartile of adiponectin or visfatin levels. inflammation through the inhibition of TNF-alpha-induced superoxide production in vascular smooth muscle cells [24], induces vasodilation [25], and plays a protective role against arterial calcification [26]. Serum omentin-1 levels were reported lower in type 2 diabetes patients with carotid plaque than in those without carotid plaque [27]. The results of these studies confirm that omentin-1 may be a good adipocytokine [25].

Regarding its effects on bone, omentin-1 inhibited osteoblast differentiation in vitro. In co-culture systems of osteoblasts and osteoclast precursors, it reduced osteoclast formation through stimulating OPG and inhibiting RANKL production in osteoblasts. In vivo, omentin-1 also attenuated bone loss induced by estrogen deficiency by lowering serum RANKL/OPG ratio [16]. Recently, we found that higher circulating omentin-1 was associated with higher BMD at the femoral neck in patients with multiple sclerosis [20].

The endothelial isoform of nitric oxide synthase (eNOS) isoform regulates osteoblast activity and bone formation and is widely expressed in bone [28]. The NO derived from the eNOS pathway acts as a mediator of the effects of estrogen in bone, and its relative deficiency may be involved in postmenopausal women [29]. Omentin-1 can stimulate the Akt-eNOS signaling pathway [30].

The extant medical literature shows sufficient in vitro and in vivo evidence indicating that omentin-1 may play a protective role in BMD. However, in the current study, omentin-1 levels had an inverse relationship with BMD at the lumbar spine in postmenopausal women. Since there is no previously reported study in postmenopausal women, the results of further work are required replicating the relationship between omentin-1 and BMD. However, recently it has been suggested that omentin-1 may exert a negative effect on bone mass in girls with anorexia nervosa [21].

Regarding the explanation for the observed inverse relationship of adiponectin (as a good adipocytokine) with BMD [31], we hypothesized that the observed higher circulating omentin-1 in lower BMD might be a physiological compensation and adaptation to protect bone from osteopenia. This explanation was suggested to explain the observed negative correlation of OPG as a protector of bone from osteopenia with BMD [32].

Visfatin has some insulin mimetic properties and antiapoptotic activity. It also has a regulatory role in inflammation [33,34]. However, its operative molecular mechanism is not fully elucidated [35]. Visfatin regulates insulin secretion, insulin receptor signaling, and mRNA expression of diabetes-related genes in mouse pancreatic beta-cells [36]. Visfatin (NAMPT)-mediated systemic nicotinamide adenine dinucleotide (NAD) biosynthesis could alter the enzymatic activities of NAD-dependent deacetylase Sirt1 and affect important metabolic pathways that are essential for regulating glucose-stimulated insulin secretion in pancreatic beta cells [37]. Recently, Li et al. [11] reported that the age-related reduction of NAMPT-mediated NAD biosynthesis and decreased Sirt1 activity could affect the determination of the lineage fate of mesenchymal stem cells in mice. Thus, they suggested that age-related reduction of NAMPT activity could be considered a possible cause for reduced osteogenesis and increased adipogenesis in older individuals [11].

A few studies in the medical literature investigated the relationship between visfatin and BMD. PBEF/NAMPT/visfatin serum levels correlated negatively with BMD in inflammatory bowel disease [38]. BMD was the predictor for visfatin in acromegaly [39]. However, no convincing data to support an association between visfatin and BMD was found in female athletes [40], Chinese men [41], and postmenopausal women [42]. Similar to these studies, no correlation between circulating visfatin and BMD at all skeletal sites was found in the current study. Interestingly, we found a significant negative correlation between bone turn over markers and circulating visfatin in postmenopausal women. Therefore, larger studies across wide age groups are warranted to evaluate visfatin in relation to BMD.

Adiponectin affects osteoblast directly and osteoclast indirectly. It stimulates the proliferation and differentiation of human osteoblasts 
via the p38 mitogen-activated protein kinase (MAPK) signaling pathway [43]. In contrast, adiponectin indirectly activates osteoclasts by stimulating RANKL and inhibiting OPG production in osteoblasts [7]. Adiponectin was associated with lower bone mass and decreased biomechanical measures of functional strength in growing mice [44].

A number of clinical studies reported the inverse association of adiponectin and BMD in women $[4,17-19,45]$. In a longitudinal study, baseline fat mass and adiponectin were associated with decreases in total bone mineral mass in older women [46]. In the Rancho Bernardo Study, adiponectin was inversely associated with BMD at the femoral neck, total hip, lumbar spine, and midshaft radius after 4.4 years and at the femoral neck and total hip almost 9 years later in postmenopausal women [47].

Likewise, in the current study, postmenopausal women with the highest quartile of serum adiponectin levels had lower lumbar BMD, compared with those who had the lowest quartile of adiponectin.

Evidence from a systemic review and meta-analysis showed that adiponectin is the most relevant adipokine negatively associated to BMD, independent of gender, menopausal status, and fat mass parameters [48]. Therefore, human studies suggest adiponectin as a negative factor for BMD. However, the increase in levels of adiponectin was hypothesized as a physiological compensation and adaptation to low BMD status [31].

We observed a positive correlation between bone turnover markers and serum adiponectin levels. In fact, age- and weight-adjusted adiponectin was significantly correlated with serum osteocalcin concentrations. Thus, adiponectin may promote a bone remodeling state. We also found that age- and BMI-adjusted to the highest quartile versus the lowest quartile of adiponectin level had a significant association with lower OPG levels. This finding is consistent with previous in vitro [7] and in vivo studies [49].

This study has several potential limitations. Since Iran is among sub regions with the highest female BMI in the World [50], the mean BMI of the randomly selected participants of our study was high $\left(\mathrm{BMI}=28.34 \mathrm{~kg} / \mathrm{m}^{2}\right)$. Adiponectin and omentin-1 are inversely related to obesity $[4,5,15]$. Therefore, finding from the current study may not be generalizable to individuals with low or normal BMI. We had no longitudinal data for the computation of longer-term effects of adipocytokines on BMD. Thus, the cross-sectional study design of our study did not allow us to examine the cumulative effects of adipocytokines and BMD over the course of the participants' lives. The changes in these adipocytokines over time could not be reflected in the current study because we assessed the investigated adipocytokines with single measurements. Since the studied adipocytokines are involved in insulin resistance and the metabolic syndrome, we did not adjust the regression models for the metabolic syndrome and measures of insulin resistance including HOMA-IR. We measured the adipocytokines in serum, and it is unclear to what extent this measurement correlates to local adipocytokine action within the bone microenvironment. The measurement of additional adipocytokines, inflammatory markers, and cytokines, including TNF-alpha, merits consideration in order to elucidate the complex system that regulates bone, fat, the immune system, and inflammation. Finally, the findings from this postmenopausal cohort may not be generalized to other sex and age groups.

In conclusion, the current study demonstrated for the first time that postmenopausal women exhibit an inverse relationship between circulating levels of omentin-1 and BMD at the lumbar spine. Although causalities cannot be determined by this cross-sectional study, we hypothesized that omentin-1 might be involved in some basic mechanisms of bone and mineral metabolism. Thus, to further understand the role of omentin- 1 in bone metabolism, large-scale longitudinal studies focusing on BMD trends and osteoporotic fracture rates, in parallel with more in vivo and in vitro detailed studies for bonespecific omentin-1 effects, are necessary in the future. Because the bone and fat interface is a promising target for the treatment and prevention of osteoporosis, it continues to attract widespread attention in current research.

\section{Funding sources}

This project was supported jointly by a grant from the Ministry of Health; Tehran Endocrine Research Center; Tehran University of Medical Science, Tehran, Islamic Republic of Iran; and Bushehr Province Research Committee.

\section{Disclosure statement}

The authors declare that they have no actual or potential conflict of interests.

\section{Acknowledgments}

The authors thank Dr. Syed Reza Imami, Shiva Mosadeghzadeh, and Zahra Amiri for assistance in the field work.

\section{References}

[1] Zaidi M, Buettner C, Sun L, Iqbal J. Minireview: the link between fat and bone: does mass beget mass? Endocrinology 2012;153:2070-5.

[2] Magni P, Dozio E, Galliera E, Ruscica M, Corsi MM. Molecular aspects of adipokinebone interactions. Curr Mol Med 2010;10:522-32.

[3] Scherer PE, Williams S, Fogliano M, Baldini G, Lodish HF. A novel serum protein similar to C1q, produced exclusively in adipocytes. J Biol Chem 1995;270:26746-9.

[4] Jurimae J, Rembel K, Jurimae T, Rehand M. Adiponectin is associated with bone mineral density in perimenopausal women. Horm Metab Res 2005;37:297-302.

[5] Dietz JJ, Iglesias P. The role of the novel adipocyte-derived hormone adiponectin in human disease. Eur J Endocrinol 2003;148:293-300.

[6] Chandran M, Phillips SA, Ciaraldi T, Henry RR. Adiponectin: more than just another fat cell hormone? Diabetes Care 2003;26:2442-50.

[7] Luo XH, Guo LJ, Xie H, Yuan LQ, Wu XP, Zhou HD, et al. Adiponectin stimulates RANKL and inhibits OPG expression in human osteoblasts through the MAPK signaling pathway. J Bone Miner Res 2006;21:1648-56.

[8] Hida K, Wada J, Eguchi J, Zhang H, Baba M, Seida A, et al. Visceral adipose tissuederived serine protease inhibitor: a unique insulin-sensitizing adipocytokine in obesity. Proc Natl Acad Sci U S A 2005;102:10610-5.

[9] Eriksson J, Franssila-Kallunki A, Ekstrand A, Saloranta C, Widen Schalin C, et al. Early metabolic defects in persons at increased risk for non-insulin-dependent diabetes mellitus. N Engl J Med 1989;321:337-43.

[10] Sonoli SS, Shivprasad S, Prasad CV, Patil AB, Desai PB, Somannavar MS. Visfatin-a review. Eur Rev Med Pharmacol Sci 2011;15:9-14.

[11] Li Y, He X, Li Y, He J, Anderstam B, Andersson G, et al. Nicotinamide phosphoribosyltransferase (Nampt) affects the lineage fate determination of mesenchymal stem cells: a possible cause for reduced osteogenesis and increased adipogenesis in older individuals. J Bone Miner Res 2011;26:2656-64.

[12] Schaffler A, Neumeier M, Herfarth H, Furst A, Scholmerich J, Buchler C. Genomic structure of human omentin, a new adipocytokine expressed in omental adipose tissue. Biochim Biophys Acta 2005;1732:96-102.

[13] Yang RZ, Lee MJ, Hu H, Pray J, Wu HB, Hansen BC, et al. Identification of omentin as a novel depot-specific adipokine in human adipose tissue: possible role in modulating insulin action. Am J Physiol Endocrinol Metab 2006;290:E1253-61.

[14] Tan BK, Adya R, Farhatullah S, Lewandowski KC, O'Hare P, Lehnert H, et al Omentin-1, a novel adipokine, is decreased in overweight insulin-resistant women with polycystic ovary syndrome: ex vivo and in vivo regulation of omentin-1 by insulin and glucose. Diabetes 2008;57:801-8.

[15] de Souza Batista CM, Yang RZ, Lee MJ, Glynn NM, Yu DZ, Pray J, et al. Omentin plasma levels and gene expression are decreased in obesity. Diabetes 2007;56: 1655-61.

[16] Xie H, Xie PL, Luo XH, Wu XP, Zhou HD, Tang SY, et al. Omentin-1 exerts bonesparing effect in ovariectomized mice. Osteoporos Int 2012;23:1425-36.

[17] Richards JB, Valdes AM, Burling K, Perks UC, Spector TD. Serum adiponectin and bone mineral density in women. J Clin Endocrinol Metab 2007;92:1517-23.

[18] Jurimae J, Jurimae T. Plasma adiponectin concentration in healthy pre- and postmenopausal women: relationship with body composition, bone mineral, and metabolic variables. Am J Physiol Endocrinol Metab 2007;293:E42-7.

[19] Wu N, Wang QP, Li H, Wu XP, Sun ZQ, Luo XH. Relationships between serum adiponectin, leptin concentrations and bone mineral density, and bone biochemical markers in Chinese women. Clin Chim Acta 2010;411:771-5.

[20] Assadi M, Salimipour H, Akbarzadeh S, Nemati R, Jafari SM, Bargahi A, et al. Correlation of circulating omentin-1 with bone mineral density in multiple sclerosis: the crosstalk between bone and adipose tissue. PLoS One 2011;6:e24240.

[21] Guo LJ, Jiang TJ, Liao L, Liu H, He HB. Relationship between serum omentin-1 level and bone mineral density in girls with anorexia nervosa. J Endocrinol Invest Jun 182012 [Epub ahead of print].

[22] Nabipour I, Larijani B, Beigi S, Jafari SM, Amiri M, Assadi M, et al. Relationship among insulinlike growth factor I concentrations, bone mineral density, and biochemical markers of bone turnover in postmenopausal women: a population-based study. Menopause 2008;15:934-9. 
[23] Liu R, Wang X, Bu P. Omentin-1 is associated with carotid atherosclerosis in patients with metabolic syndrome. Diabetes Res Clin Pract 2011;93:21-5Diabetes Res Clin Pract.

[24] Kazama K, Usui T, Okada M, Hara Y, Yamawaki H. Omentin plays an antiinflammatory role through inhibition of TNF-alpha-induced superoxide production in vascular smooth muscle cells. Eur J Pharmacol 2012;686:116-23Eur J Pharmacol.

[25] Yamawaki H. Vascular effects of novel adipocytokines: focus on vascular contractility and inflammatory responses. Biol Pharm Bull 2011;34:307-10.

[26] Duan XY, Xie PL, Ma YL, Tang SY. Omentin inhibits osteoblastic differentiation of calcifying vascular smooth muscle cells through the PI3K/Akt pathway. Amino Acids 2011:41:1223-31.

[27] Yoo HJ, Hwang SY, Hong HC, Choi HY, Yang SJ, Seo JA, et al. Association of circulating omentin-1 level with arterial stiffness and carotid plaque in type 2 diabetes. Cardiovasc Diabetol 2011;10:103.

[28] van't Hof RJ, Ralston SH. Nitric oxide and bone. Immunology 2001;103:255-61.

[29] Wimalawansa SJ. Nitric oxide: novel therapy for osteoporosis. Expert Opin Pharmacother 2008;9:3025-44.

[30] Maruyama S, Shibata R, Kikuchi R, Izumiya Y, Rokutanda T, Araki S, et al. Fat-derived factor omentin stimulates endothelial cell function and ischemia-induced revascularization via endothelial nitric oxide synthase-dependent mechanism. J Biol Chem 2012;287:408-17.

[31] Kanazawa I. Dose Adiponectin have adverse effects on bone mass and fracture? Internal Med: Open Access 1:e101. http://dx.doi.org/10.4172/ime.1000e101.

[32] Samelson EJ, Broe KE, Demissie S, Beck T], Karasik D, Kathiresan S, et al. Increased plasma osteoprotegerin concentrations are associated with indices of bone strength of the hip. J Clin Endocrinol Metab 2008;93:1789-95.

[33] Saddi-Rosa P, Oliveira CS, Giuffrida FM, Reis AF. Visfatin, glucose metabolism and vascular disease: a review of evidence. Diabetol Metab Syndr 2010;2:21.

[34] Stephens JM, Vidal-Puig AJ. An update on visfatin/pre-B cell colony-enhancing factor, an ubiquitously expressed, illusive cytokine that is regulated in obesity. Curr Opin Lipidol 2006;17:128-31.

[35] Akbarzadeh S, Nabipour I, Jafari SM, Movahed A, Motamed N, Assadi M, et al. Serum visfatin and vaspin levels in normoglycemic first-degree relatives of Iranian patients with type 2 diabetes mellitus. Diabetes Res Clin Pract 2012;95:132-8.

[36] Brown JE, Onyango DJ, Ramanjaneya M, Conner AC, Patel ST, Dunmore SJ, et al. Visfatin regulates insulin secretion, insulin receptor signalling and mRNA expression of diabetes-related genes in mouse pancreatic beta-cells. J Mol Endocrinol 2010;44: 171-8.

[37] Revollo JR, Ko“ rner A, Mills KF, Satoh A, Wang T, Garten A, et al. Nampt/PBEF/ visfatin regulates insulin secretion in beta cells as a systemic NAD biosynthetic enzyme. Cell Metab 2007;6:363-75.
[38] Moschen AR, Geiger S, Gerner R, Tilg H. Pre-B cell colony enhancing factor/ NAMPT/visfatin and its role in inflammation-related bone disease. Mutat Res 2010;690:95-101.

[39] Sucunza N, Barahona MJ, Resmini E, Fernández-Real JM, Ricart W, Farrerons J, et al. A link between bone mineral density and serum adiponectin and visfatin levels in acromegaly. J Clin Endocrinol Metab 2009;94:3889-96.

[40] Gruodyte R, Jurimae J, Cicchella A, Stefanelli C, Passariello C, Jürimäe T. Adipocytokines and bone mineral density in adolescent female athletes. Acta Paediatr 2010;99:1879-84.

[41] Peng XD, Xie H, Zhao Q, Wu XP, Sun ZQ, Liao EY. Relationships between serum adiponectin, leptin, resistin, visfatin levels and bone mineral density, and bone biochemical markers in Chinese men. Clin Chim Acta 2008;387:31-5.

[42] Zhang H, Xie H, Zhao Q Xie GQ, Wu XP, Liao EY, et al. Relationships between serum adiponectin, apelin, leptin, resistin, visfatin levels and bone mineral density, and bone biochemical markers in post-menopausal Chinese women. J Endocrinol Invest 2010;33:707-11.

[43] Luo XH, Guo LJ, Yuan LQ, Xie H, Zhou HD, Wu XP, et al. Adiponectin stimulates human osteoblasts proliferation and differentiation via the MAPK signaling pathway. Exp Cell Res 2005;309:99-109.

[44] Ealey KN, Kaludjerovic J, Archer MC, Ward WE. Adiponectin is a negative regulator of bone mineral and bone strength in growing mice. Exp Biol Med (Maywood) 2008;233:1546-53.

[45] Napoli N, Pedone C, Pozzilli P, Lauretani F, Ferrucci L, Incalzi RA. Adiponectin and bone mass density: the InCHIANTI study. Bone 2010;47:1001-5.

[46] Jurimae J, Kums T, Jurimae T. Adipocytokine and gherlin levels in relation to bone mineral density in physically active older women: longitudinal associations. Eur J Endocrinol 2009;160:381-5.

[47] Araneta MR, von Muhlen D, Barrett-Connor E. Sex differences in the association between adiponectin and BMD, bone loss, and fractures: the Rancho Bernardo study. J Bone Miner Res 2009;24:2016-22.

[48] Biver E, Salliot C, Combescure C, Gossec L, Hardouin P, Legroux-Gerot I, et al. Influence of adipokines and gherlin on bone mineral density and fracture risk: a systematic review and met-analysis. J Clin Endocrinol Metab 2011;96:2703-13.

[49] Sodi R, Hazell MJ, Durham BH, Rees C, Ranganath LR, Fraser WD. The circulating concentration and ratio of total and high molecular weight adiponectin in post-menopausal women with and without osteoporosis and its association with body mass index and biochemical markers of bone metabolism. Clin Biochem 2009;42:1375-80.

[50] Finucane MM, Stevens GA, Cowan MJ, Danaei G, Lin JK, Paciorek CJ, et al. National, regional, and global trends in body-mass index since 1980: systematic analysis of health examination surveys and epidemiological studies with 960 country-years and 9.1 million participants. Lancet 2011;377:557-67. 